\title{
Comparative Physicochemical Study of the Thermally and Thermo-oxidatively Decomposed Automotive Crankcase Oils
}

\author{
Anietie E. Ekot ${ }^{1}$, Goodwill C. Ofunne ${ }^{2}$ and Edet W. $\mathrm{Nsi}^{3}$ \\ ${ }^{1}$ (Department of Chemistry, Akwa Ibom State University, Ikot Akpaden, P.M.B.1167 Uyo, Akwa Ibom \\ State, Nigeria) \\ ${ }^{2}$ (Department of Pure and Industrial Chemistry, University of Port Harcourt, Port Harcourt Rivers State, \\ Nigeria) \\ ${ }^{3}$ (Department of Chemistry, Akwa Ibom State University, Ikot Akpaden, P.M.B.1167 Uyo, Akwa Ibom State, \\ Nigeria)
}

\begin{abstract}
The performance characteristics of the automotive crankcase oil, be it of synthetic or natural origin is basically a function of its stability at the engine operation temperature. The performance characteristics usually drop with aging occasioned by a combination of thermal and thermo-oxidative decomposition. The two modes oil degradation have been investigated by simulating those conditions encountered in the automotive crankcase engines under normal operation. Two commercially available multigrade crankcase lubricants (synthetic oil and mineral blend) were subjected to thermal and thermo-oxidative decomposition using a modified version of the turbine oil oxidation test apparatus. Thermal decomposition was carried out in the absence of air while thermo-oxidative degradation was achieved with an air flow rate of 1.0 litre per hour for 15hours. The physicochemical changes in oil composition were evaluated by measuring the Total Acid Number (TAN), Total Oxidation Products (TOP) and the infra-red spectral changes of the decomposition products at various temperatures ranging from $100^{\circ} \mathrm{C}$ to as high as $380^{\circ} \mathrm{C}$. The results indicated that the mineral oil showed a higher aging characteristics in both the thermal and thermo-oxidative decomposition than its synthetic multigrade counterpart. The infra-red analysis revealed that the physicochemical changes associated with aging of the oil samples at high temperature were mainly due to the breakdown of additives and hydrocarbon matrix at the onset of aging into monomeric fragments of peroxides, organic acids and carbonyl compounds which polymerize at a much higher temperature into dark resinous materials. The physicochemical changes with temperature may therefore be used in evaluating the temperature-related aging hence the thermal and thermooxidative stabilities as well as the performance characteristics of crankcase lubricants.
\end{abstract}

Keywords: Mineral blend, Synthetic oil, decomposition, physicochemical changes

\section{Introduction}

Under normal engine operating conditions lube oils are subjected to combination of both thermal and oxidative decomposition leading to the breakdown of additives such as antioxidants [1] In most cases the temperatures can be in the of range $90^{\circ} \mathrm{C}$ at the connecting rod cylinder to about $430^{\circ} \mathrm{C}$ at the piston crown [2] Consequently, the oil stability drops. And if this continues to a point where the oil is incapable of reducing the force of friction between the moving surfaces in contact, a point where the oil has lost its viscosity due to the decrease in intermolecular forces of attraction between the oil molecules[3], the engine becomes overheated leading to metallic rattling, a mechanochemical disorder known as knocking. Thus, modern engine design imposes stringent requirements on the physicochemical characteristics of lube oils [4] to ensure high performance under severe temperature regimes. However, at certain critical temperatures the performance capabilities of oil are lost considerably due to mechanochemical reactions between the oil molecules and the antioxidants. These reactions are responsible for the formation of volatile acid compounds and polymeric products deposited as sludge in valve trains [5].

In modern tribology oil performance levels are defined by the engine dynometer tests, which measures the stability of base oil. One example of such tests is the sequence IIID test which measures the high temperature decomposition of engine oil [6]. Recent study [7] has listed some of the problems besetting this test to include the multivariant nature of factors that affect oil decomposition during service. Consequent upon this set back a number of proprietary tests based on the simulation of the engine operating conditions have been developed. The test is simply designed to reproduce the engine oil performance in the laboratory [8].

By this method a decrease in the performance characteristics associated with the physicochemical changes in lube oils during service have been measured by [9] with high degree of accuracy using standard Turbine Oil Oxidation Test (TOOT) apparatus.

In this research a modified version of the open test tube type of oxidation apparatus was used to study some physicochemical characteristics of both mineral and synthesis lube oils. The work was aimed at isolating 
and quantifying sludge deposits and the volatile oil fragments formed at various temperatures. The type and the amount of these fragments were used to assess the physicochemical changes, hence the thermal and the thermooxidation stability of the lubricants. The method evaluates the level of oil deterioration at selected temperatures based on sludge deposits of the oxidates, total acid number, total oxidation products and infrared characteristics of the oxidates. Taken together, these parameters have given a sharp picture of the physicochemical changes that occurred at the molecular level when the lube oils are subjected to high temperatures under a simulated engine operating conditions.

\subsection{Materials}

\section{Experimental}

Two grades of automotive oils commonly used in the spark ignition internal combustion engines were sourced locally for this work. The SAE-20W50 multigrade lube oil, representing the mineral oil blend was obtained from the then Elf Petroleum (Nig) Ltd while the GT-10W40 Multigrade representing the synthetic base-stock, was obtained from Lenoil Petroleum and Petrochemicals (Nig) Ltd, all in Port-Harcourt Rivers State, Nigeria. Some of the characteristics of the mineral oil and its synthetic counterpart are given in tables 1 and 2. All reagents used in this work which were either obtained from the university of Port-Harcourt chemical store or purchased from standard chemical departments, conformed with analytical grades.

\subsection{Experimental procedure}

The method used in measuring the physicochemical changes in high temperature oxidation of mineral oil and synthetic lubricants has been described elsewhere (Ofunne et al, 1989) but the modified version of the standard Turbine Oil Oxidation Tests (TOOT) apparatus was developed in our laboratory for the purpose of this work. The procedure involves thermal oxidation of the oil samples using a thermostatically regulated heating mantle with a maximum heating capacity of $450^{\circ} \mathrm{C}$. The oxidation process was carried out in a three-necked flask $\left(500 \mathrm{~cm}^{3}\right)$ in which the oil samples were heated at different temperature intervals from ambient to about $380^{\circ} \mathrm{C}$ with an airflow of 1.0 litre/hr. The temperature of oil was raised by $40^{\circ} \mathrm{C}$ after every 2.5 hours and the oxidate sample withdrawn, quenched and stored in a fridge. The volatiles were also withdrawn at every test temperature interval and trapped in a second flask containing $200 \mathrm{~cm}^{3}$ of freshly prepared $0.1 \mathrm{MKOH}$ solution.

The oil samples were analysed for Total Acid Number (TAN), which was determined from a combination of oil soluble and volatile acidity. Also analysed for were sludge deposits (measured as n-heptane insolubles) and Total Oxidation Products (TOP). All the parameters were measured in accordance with the American Society of Test and Materials method D-664(IP1980). Infra red spectroscopy was also used as an additional tool to fully evaluate at the molecular level the changes in the physicochemical characteristics of the decomposition products at various test temperatures regimes.

\section{Results And Discussions}

\subsection{Total acid number}

The physicochemical changes in high temperature oxidation of mineral oil and synthetic lube oils have been investigated. The evaluation of the changes was accomplished by carrying out the thermooxidation stability tests on the samples using a simple model or the modified version of Turbine Oil Oxidation Tests (TOOT) apparatus earlier mentioned in the procedure. The details of the results are given below. The graph in fig. 1 shows the changes in total acid number with temperature. Between 140 and $220^{\circ} \mathrm{C}$ mineral oil showed little or no changes in acidity, until about $300^{\circ} \mathrm{C}$ where the acidity increased almost exponentially. Whereas synthetic oil showed no appreciable increase in acidity even at high temperature regime. The sharp increase in soluble acidity of the mineral oil can be attributed to the formation of the oxidation products which may include peroxides, carboxylic acids and carbonyl compounds. Synthetic oil on the other hand showed a high degree of high temperature stability probably due to the type of hydrocarbons used in formulating its base stock coupled with the action of the high temperature resistant additives incorporated in it. At much higher temperatures the rate of auto oxidation reactions leading to the formation of more oxygenated products such as alcohols and hydroperoxides. However the dicernable regime of acidity changes for the three samples are consistent with those demarcated in the study of jet oil [10].

\subsection{Sludge deposits measurement}

The sludge deposits of the oxidates measured as the per- centage of the materials insoluble in normal heptane comprised all high molecular weight (HMW) polymeric products otherwise known as resins. These products resulted from the high temperature thermooxidative degradation of the oil molecules and their additives. The results of the sludge deposits obtained for the oil samples were plotted as a function of temperature (fig.2). The profile shows that at low temperatures between $120^{\circ} \mathrm{C}$ and $180^{\circ} \mathrm{C}$ only very little sludge was formed. It was particularly observed that no sludge was formed from the fully formulated synthetic oil 
while only a very small amount of sludge was observed for mineral oil. However, between $180^{\circ} \mathrm{C}$ and $260^{\circ} \mathrm{C}$, there was a gradual sludge formation by all the samples with mineral oil being more susceptible to temperature increase than its synthetic counterpart as its sludge formation became exponential without a corresponding increase for the synthetic oil. However a slight increase was also observed for the synthetic blend at $300^{\circ} \mathrm{C}$. The low sludge level in the synthetic oil could be due to the fact that at very high temperature the synthetic oil sludge decomposes into smaller fragments which are collected as volatiles. Another factor that may have contributed to low sludge content in synthetic lube is the high concentration of the dispersants [11]. The activities of dispersants according to Asseff could hinder the settling of the sludges as they are being formed. The difference in sludge formation between the samples can be explained at molecular level by the compositional structure and steric factors [12]. The synthetic oil generally contains more substituted aromatic and naphthenic hydrocarbons which are resonance stabilized even at relatively high temperatures. While mineral oils are richer in aliphatic hydrocarbons which are quite vulnerable to high temperature reactions such as polymerization.

Fig. 3 depicts variations in the total oxidation products which include all the products irrespective of their chemical origins, that were formed as a result of oxidative degradation of the oil samples. These products give a clear indication of the total conversion of the hydrocarbons and the overall extent of oxidation that occurred at various test temperatures.

\subsection{Total oxidation products measurement}

The total oxidation products of the oil samples were obtained by summing up all the oxidation products namely, the volatile acidity and the soluble acidity of the oil samples for both thermal and thermooxidative decomposition tests and the results (Table 3 ) shows that the total oxidation product for mineral oil is higher than that of the synthetic oil. This again strongly indicates that the synthetic oil blend is both thermally and thermo-oxidatively more stable than the mineral oil blend.

\subsection{Infrared spectra}

Infrared spectroscopy has been used to detect the presence of oxidation products in used oil samples [13]. The use of computer aided infrared spectroscopy to measure the total oxidation products by integrated area calculations has proved quite successful in the recent time [14]. In this work infrared studies were also used to evaluate the level physicochemical changes in the oil samples at various temperatures ranging from ambient up to $380^{\circ} \mathrm{C}$.

Fig. 4 depicts the physicochemical changes in the spectra for the two samples. Figs. $4 \mathrm{a}$ and $\mathrm{b}$ represent the spectra for mineral oil and synthetic oil respectively. The spectra obtained were used to study the molecular conditions of the oil samples at various levels of thermal and thermo-oxidative decomposition. The absorption peaks of interest are those due to oxidation products at different vibrational frequencies of $3500 \mathrm{~cm}^{-1}-3400 \mathrm{~cm}^{-1}$, $3000 \mathrm{~cm}^{-1}-2900 \mathrm{~cm}^{-1}, 1800 \mathrm{~cm}^{-1}-1700 \mathrm{~cm}^{-1}$ and $1000 \mathrm{~cm}^{-1}-900 \mathrm{~cm}^{-1}$. The absorptions between $3500 \mathrm{~cm}^{-1}$, $340 \mathrm{~cm}^{-1}$ indicate the presence of alcohols or organic acid in the oil samples. But any absorption in this region by the samples at low temperatures may be due to hydroxyl groups present in phenolic additives, since there could be no reaction leading to the formation of alcohols at those temperatures. Absorption in this region diminishes slowly with increase in temperature showing that hydroxyl groups are being lost due to interaction with other functional groups during oxidation. At about $260^{\circ} \mathrm{C}$ the synthetic oil gave a more prominent peak suggesting the formation of alcoholic species as primary oxidation products. Above this temperature regime the peak diminishes indicating the gradual disappearance of alcohols as a component of volatile products. Absorptions between $1800 \mathrm{~cm}^{-1}-1700 \mathrm{~cm}^{-1}$ are due to formation of carbonyl species. The absorption intensity increased as the rate of thermooxidative degradation reaction increased steadily with rise in temperature. However the mixed stock blend gave no noticeable band up to $260^{\circ} \mathrm{C}$. This may be due to interactions between the additive blends in the mixture which might result in the carbonyl band interference. At $300^{\circ} \mathrm{C}$ the mixed stock gave a small absorption peak with increased intensity at $340^{\circ} \mathrm{C}$. Above this temperature all the samples showed either diminished or broad peaks, indicating the involvement of carbonyls in high temperature processes such as polymerization and other complex reactions leading to the formation of high molecular weight products. This observation agrees with the reports by [15] that the main reactions at the later stage oil deterioration involve adol-type condensation resulting in the formation of high molecular weight resinous products. It must be noted however that the formation of various carbonyl compounds such as Ketones absorbing at $1750 \mathrm{~cm}^{-1}$, conjugated ketones $\left(1675 \mathrm{~cm}^{-1}\right)$, aldehydes $\left(1725 \mathrm{~cm}^{-1}\right)$, organic acids $\left(1710 \mathrm{~cm}^{-1}\right)$, carboxylates $\left(1610-1550 \mathrm{~cm}^{-1}\right)$, esters $\left(1745-1725 \mathrm{~cm}^{-1}\right)$ are all influenced by temperature and chemical composition of the lubricants.

\section{Conclusion}

The results of the investigation based on the physicochemical changes in the hydrocarbon matrix of the oils at high temperature indicate that the mineral oil has the lowest thermal oxidation stability, probably due to high concentration of parafinnic hydrocarbons which are known to be more thermally unstable than the 
naphthemic and aromatic species which of course form the bulk of hydrocarbons in synthetic oil. Based on these findings synthetic lubricants have been recommended for high temperature operations in the spark ignition internal combustion engines, provided the quality and quantity of additives incorporated are the same as in the two grades of lube oil blends studied.

Table 1

Some of the typical characteristics of multigrade mineral oil (Lenoil Brochure, 1990)

\begin{tabular}{lcl}
\hline Parameter & - & Mineral oil \\
$\mathrm{SAE}$ Classification & - & SAE 20W50 \\
Appearance & - & Clear Amber \\
Specific Gravity at $15^{0} \mathrm{C}$ & - & 0.89 \\
Viscosity Index $(\mathrm{VI})$ & - & 130.00 \\
Viscosity at $100^{0} \mathrm{C}(\mathrm{cSt})$ & - & 18.20 \\
Total acid number $\mathrm{mgKOHg}^{-1}$ & - & 0.44 \\
\hline
\end{tabular}

Table 2

Some of the typical characteristics of multigrade synthetic oil (Lenoil Brochure, 1990)

\begin{tabular}{lcl}
\hline Parameter & & Synthetic oil \\
SAE Classification & - & SAE 10W40 \\
Appearance & - & Clear Amber \\
API Gravity & - & 26.40 \\
Pour point $\left(^{\circ} \mathrm{C}\right)$ & - & -37 \\
Viscosity at $100^{0} \mathrm{C}(\mathrm{cST})$ & - & 14.10 \\
Total acid number $\mathrm{mgKHg}^{-1}$ & - & 0.44 \\
Total base number $\mathrm{mgKOHg}^{-1}$ & - & $\underline{6.30}$ \\
\hline
\end{tabular}

Table 3

Physicochemical characteristics of the oil samples at $360^{\circ} \mathrm{C}$ after $15 \mathrm{hrs}$ test period

\begin{tabular}{lllll}
\hline Oil sample & $\begin{array}{l}\text { Soluble acidity } \\
\mathrm{mgKOH} / \mathrm{g}\end{array}$ & $\begin{array}{l}\text { Volatile acidity } \\
\mathrm{mgKOH} / \mathrm{g}\end{array}$ & Pentane insolubles $\mathrm{Wt} \%$ & Colour of the samples \\
\hline Mineral oil (MO) & 0.946 & 0.896 & 14.52 & Dark brown \& Waxy \\
Synthetic oil (SO) & 0.831 & 0.715 & 6.45 & Dark brown \\
\hline
\end{tabular}
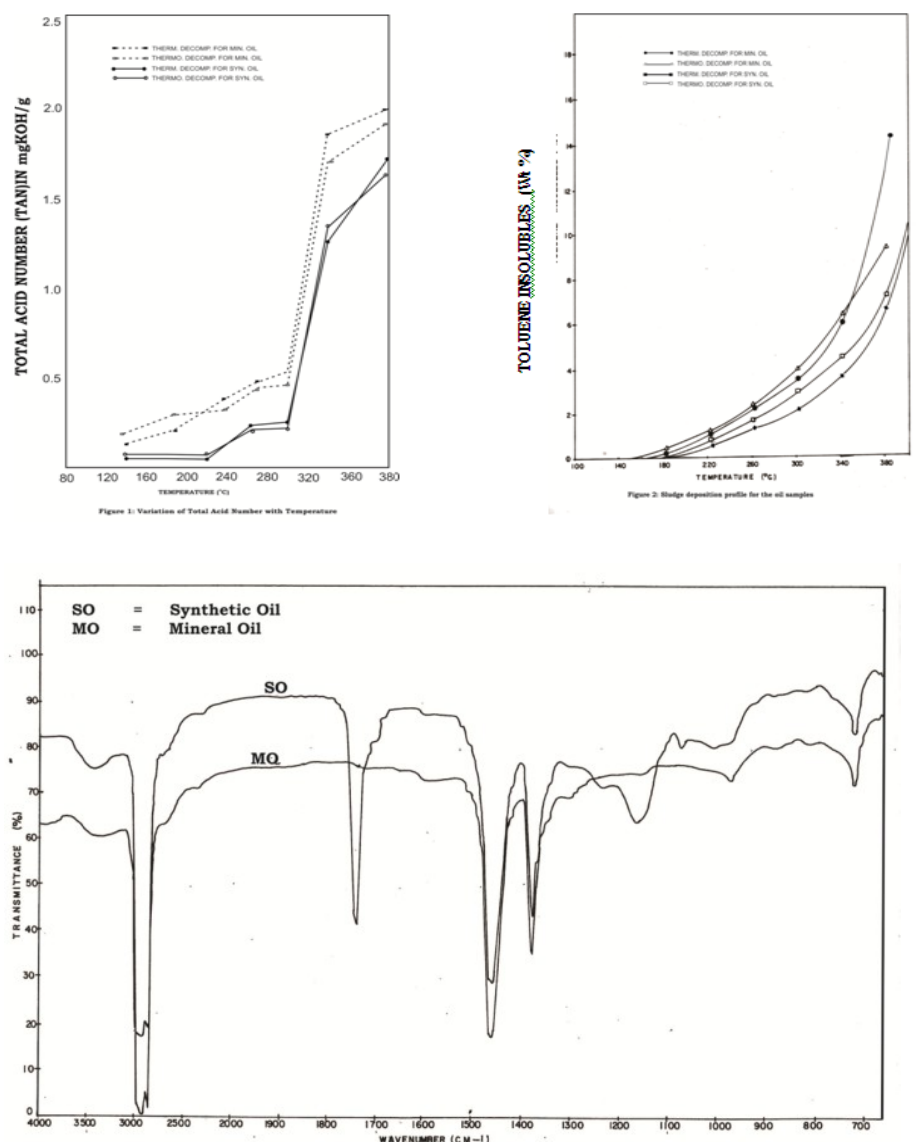

Figure 3: The Infrared Spectra of the Oil Samples at Ambient Temperature 

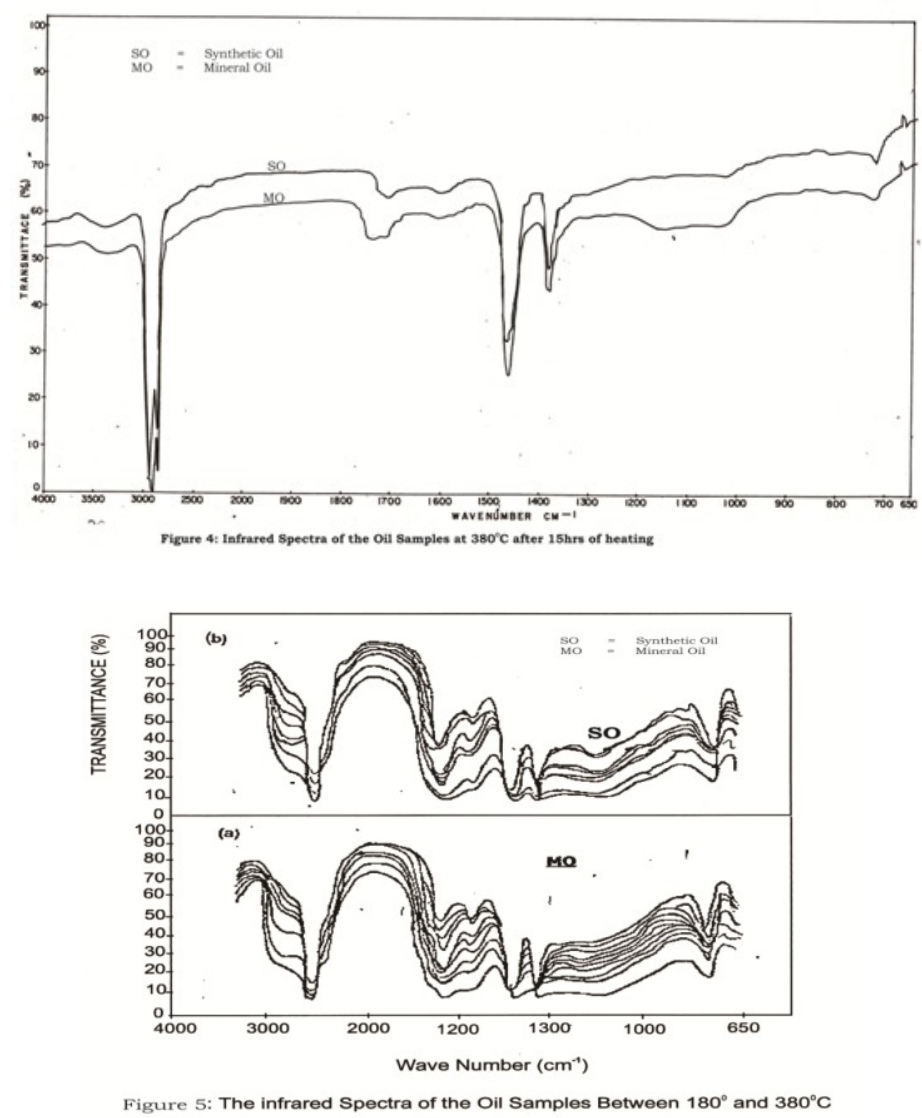

\section{References}

[1]. Korcek, S., Jensen, R. K. and Zimbo, M. (1980). Determination of the High Temperature Anti-oxidant capability of Lubricant Components. Industry \& EC Prod. Res. Dev., 25:pp.617 - 623.

[2]. Gruse, W. A., (1967). Motor Oil Performance and Evaluation. Reinhold, NY, U.S.A., pp.73-79.

[3]. Chawla,S.Engineering Chemistry (Third Edition, Gagankapur for Dhanpatrai \& Coy:Delhi,2003)

[4]. McGrechan, D. J.(1979). A Survey of mechanical design parameters affecting engine oil consumption. Soc. Am. Engr. Paper No. 790864: pp. $35-38$.

[5]. Jensen, R. K., Korcek, S., Mahoney, L. R. and Zimbo, M.(1981). Phase Auto-oxidation of organic compounds at elevated temperature 2: Kinetics and mechanisms of formation of cleavage products in n-hexadecane Auto-oxidation, J. Am. Chem. Soc. 103: $17-42$.

[6]. Rodgers, J. J. and Kabel, R. H., 1978. A Revised Sequence HIC Engine oil test. Soc. Am. Engr. Paper No. 780259. Congress \& Exposition, Feb. 27 - Mar. 3. pp. 29-36.

[7]. Ofunne, G. C., Maduako A. U and Ojinnaka, C. M.(1989). The ageing characteristics of automotive crankcase oils. Tribalogy International 12(6):401-405.

[8]. Johnson, M. D., Korcek, S. and Zimbo, M.(1987). High Temperature anti-oxidant capabilities of base oils and base oil additive mixtures. Industr. Engrg. Chem. Prod. R\&D, 26:1754-1759.

[9]. Wellermet P. A., Mahoney I. R. and Bishop C. N. (1980) Lubricant degradation and wear II, antioxidant capacity and I.R spectra in system containing ZDTP, ASIE Trans, 23: 217 - 224.

[10]. Hazlett, R. N. (1980). Free Radical Reactions Related to Fuel research in Frontiers of Free Radical Chemistry. Academic Press, New York U.S.A., p.195.

[11]. Asseff, P. A. (1975). Lubrication Theory and Plactice. An International Publication for the Lubrizol Corp. Lakeland Boulevard Wickliffe, Ohio, U.S.A., pp13-19.

[12]. Ofunne, G. C., Maduako A. U. and Ojinnaka, C. M.(1990). High Temperature oxidation stability of automotive crankcase oils and their base oils. Tribology International, 23(6): $407-412$.

[13]. Barcelo, J. R and Otero, C.(1964). A Spectrophometric Method for Studying the Oxidation of Lubricating Oils. J. Inst. Petroleum. 50(15): 481-483.

[14]. Wooten, D. L., Lawrence, B. J. and Damrath, J. C.(1984). Integreted Analysis of heavy duty Diesel Engine oils. Soc. Am. Engr. Paper No. 841372: 71-79.

[15]. Klaus, E. E., Cho, L. and Dang, H.(1980). Adaption of Pure State Micro-oxidation tests for evaluation of automotive lubricants. S. A. E. Paper No. 8013362: pp. 78 -85. 